\title{
Repensando las clasificaciones socio-étnicas del siglo XVIII. Indios, mestizos y españoles al sur del valle Calchaquí (Argentina)
}

\author{
Lorena B. Rodríguez \\ Conicet / Universidad de Buenos Aires, Argentina \\ rodriguezlo@hotmail.com
}

\begin{abstract}
Resumen
A partir del análisis de la composición poblacional del valle de Santa María (noroeste argentino) durante el siglo XVIII, el objetivo de este artículo es repensar el problema de las clasificaciones socio-étnicas. En ese sentido, a la vez que centramos nuestra propuesta en un debate teórico-metodológico acerca del tipo de fuentes que utilizamos o la forma como lo hacemos o lo hicieron otros investigadores, pretendemos historizar y contextualizar el uso de algunas categorías como indio, español y mestizo para evidenciar que - más allá de los intereses de la Corona o de las élites locales - las mismas resultaron ser muy móviles y flexibles, y que fueron cambiando y entretejiendo nuevos sentidos a la luz de múltiples factores.
\end{abstract}

Palabras clave: población, clasificaciones socio-étnicas, Santa María, siglo XVIII.

\begin{abstract}
Based on the analysis of the population composition of Santa María valley (Argentine Northwest) during the 18th century, the aim of this paper is to rethink the problem of socio-ethnic classifications. In that sense, while focusing our proposal in a theoretical and methodological debate about the kind of sources that we use, how we do it or did other researchers; we intend to historicize and contextualize the use of certain terms as indian, spanish and mestizo in order to demonstrate that - beyond the interests of the Crown and / or local elites - these categories turned out to be highly mobile and flexible and that they were changing and interweaving new senses in the light of many factors.
\end{abstract}

Key words: population, socio-ethnic classifications, Santa María, 18th century. 


\section{Introducción}

Desde los primeros años de la conquista de América la administración colonial impuso una "taxonomía" de la sociedad americana. El ordenamiento colonial, fuertemente estratificado y jerarquizado, fue pensado en torno a una división fundamental: conquistadores versus conquistados. Esto llevó a definir nuevas identidades socio-étnicas, a redefinir otras ya existentes y a establecer como principio de orden el funcionamiento de la República de indios separada de la República de españoles. Pronto fue evidente que tal división era solo un ideal. En la práctica, las fronteras entre ambas repúblicas fueron totalmente permeables y dieron cuenta de una compleja realidad que, en especial los Borbones hacia la segunda mitad del siglo XVIII, trataron de regular propiciando una estricta clasificación de la población.

A partir del análisis de la composición poblacional del valle de Santa María ${ }^{1}$ durante el siglo XVIII, el objetivo de este artículo es repensar el problema de las categorizaciones socio-étnicas. En ese sentido, a la vez que centramos nuestra propuesta en un debate teórico-metodológico acerca del tipo de fuentes que utilizamos o la forma como lo hacemos o lo hicieron otros investigadores, pretendemos historizar y contextualizar el uso de algunas categorías como indio, español y mestizo para evidenciar que - más allá de los intereses de la Corona o de las élites locales - las mismas resultaron ser muy móviles y flexibles, y que fueron cambiando y entretejiendo nuevos sentidos a la luz de múltiples factores.

Este trabajo forma parte de la investigación doctoral (Rodríguez), cuyo objetivo fue analizar el proceso de reconfiguraciones socio-económicas y étnicas en el valle de Santa María luego de la desnaturalización de las poblaciones indígenas locales, ocurrida hacia 1665 como consecuencia de la finalización de las guerras calchaquíes ${ }^{2}$. Así, nuestra zona de estudio se erige como un espacio de análisis interesante para abordar el tema de las clasificaciones socio-étnicas no solo por la situación particular de la que partimos (las desnaturalizaciones y el supuesto "vaciamiento"3 del valle), sino también porque aunque en Santa María nunca se constituyeron

$1 \quad$ El valle de Santa María se encuentra ubicado en el actual noroeste argentino y constituye el sector meridional del valle Calchaquí (véase Mapa 1). Está delimitado al oeste por las sierras del Cajón o de Quilmes y al este, por la sierra del Aconquija. En la actualidad pertenece principalmente a la provincia argentina de Catamarca.

2 La penetración hispana en el valle Calchaquí fue muy particular, debido a la resistencia de las poblaciones locales. Recién en 1665, y después de 130 años de lucha, los españoles vencieron a los distintos grupos indígenas aplicándoles el castigo de trasladarlos compulsivamente (proceso de desnaturalización). El tema de las rebeliones calchaquíes ha sido tratado por diversos autores. Véanse Montes, Piossek Prebisch, Lorandi $(1988,1997,2000)$ y Lorandi y Boixadós, entre otros.

3 En otro trabajo hemos discutido la idea del vaciamiento del valle (Rodríguez). 
pueblos de indios (en términos de reducción colonial), a fines del siglo XVIII buena parte de la población allí asentada seguía siendo clasificada como indígena.

Nuestras fuentes principales han sido las actas de defunciones, bautismos y matrimonios y los Libros de Fábricas y Censos depositados en el Archivo Parroquial de Santa María (APSM), así como los censos generales de población de 1771 y 1812, las revisitas de indios de fines del siglo XVIII y algunos documentos alternativos (informes de curas, expedientes notariales, entre otros).

En líneas generales, la metodología utilizada combinó las perspectivas antropológica e histórica. El análisis de los datos fue principalmente cualitativo, partió de una mirada dinámica y procesual del pasado (Lorandi y del Río) y, cuando los datos recabados así lo requirieron, se acudió también al análisis cuantitativo. Con el fin de superar los sesgos o debilidades propias de cada fuente, hemos recurrido a la "triangulación de datos", que consiste "en verificar datos por medio de varios documentos y otras fuentes" (Langer 178).

\section{Mapa 1. Ubicación de los valles Calchaquí}

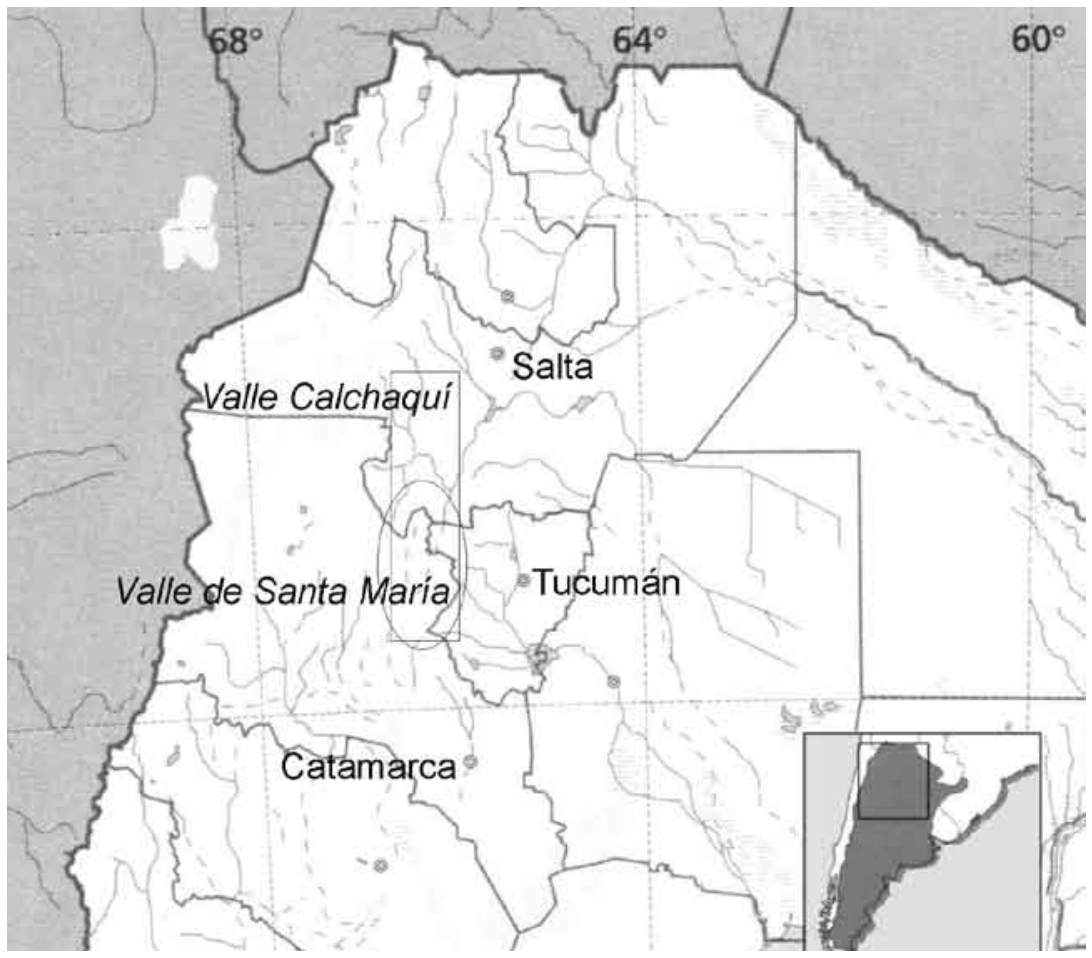

Fuente: elaboración de la autora. 


\section{La composición socio-étnica de Santa María: una discusión sobre los criterios de clasificación}

El abordaje de la composición socio-étnica de cualquier población es un tema complejo. Al problema de la escasez o disparidad de fuentes sumamos el ya clásico inconveniente de saber cuáles fueron los criterios de clasificación con base en los que se "encasilló" a las personas en uno u otro estatus socio-étnico, según los momentos, espacios, actores sociales o intereses involucrados ${ }^{4}$. Distintos criterios construyen imágenes diferentes de la sociedad. Como veremos, la dificultad no solo proviene del desconocimiento que tenemos acerca de los parámetros utilizados por curas o censistas, sino, también, de la confusión que se genera a partir de los distintos parámetros que utilizamos los investigadores.

La composición socio-étnica de la población de Santa María en la primera mitad del siglo XVIII es un tema de difícil abordaje; en particular, si pretendemos hacerlo con base en los datos protoestadísticos que tenemos. Prácticamente, el único documento disponible es el Libro de Fábricas de Entierros, llevado por el mayordomo eclesiástico entre 1716 y $1734^{5}$, que nos ofrece solo una aproximación a la temática que resumimos en el siguiente cuadro:

\section{Cuadro 1 : Composición socio-ética según defunciones (1716-1734)}

\begin{tabular}{|c|c|c|}
\hline \multicolumn{3}{|c|}{ Estatus socio-étnico } \\
\hline Indios & Españoles & Sin identificar \\
\hline 29 & 3 & 19 \\
\hline
\end{tabular}

Fuente: Elaboración propia, con base en el Libro de Fábrica de Entierros (Manuscrito Larrouy).

En líneas generales, los datos recogidos en el cuadro nos muestran que el único estatus socio-étnico que aparece claramente detallado es el de indio, y que las personas enterradas en Santa María durante esos primeros años pertenecieron mayoritariamente a esa categoría. En segundo lugar, que los españoles constitu-

$4 \quad$ El tema de las clasificaciones socio-étnicas ha sido tratado ampliamente y desde diversas perspectivas. Para el espacio novohispano, baste con citar los ya clásicos trabajos de Chance y MacCaa, o los más recientes de Castillo Palma y Gonzalbo Aizpuru. También para el NOA pueden encontrarse referencias en Guzmán, Gil Montero, López de Albornoz, entre otros que, por cuestiones de espacio, no podemos desarrollar.

5 Manuscrito Larrouy, "Memoria de los que se hacen enterrar en dicha capilla de Santa María desde 1716", mayordomo eclesiástico Ambrosio Muñiz Cancinos. Este manuscrito contiene las transcripciones de diversos documentos sobre el valle santamariano, que recogió el padre Larrouy a principios del siglo XX. 
yeron una porción ínfima de la población. Por último, que una parte importante de la población no fue rotulada bajo ningún estatus socio-étnico determinado.

Ahora bien, en este punto es necesario hacer algunas aclaraciones en cuanto a los criterios elegidos para elaborar el cuadro. En primer lugar, colocamos bajo el rótulo de indios a aquellos que así fueron designados por el mayordomo eclesiástico y a los niños para los cuales no se detalló estatus socio-étnico, pero cuyo padre o cuya madre fueron clasificados como indios. En segundo lugar, fueron considerados como españoles aquellos para los que se agregó la partícula don o doña o el "cargo militar", y también los niños a los que no se les asignó estatus, pero cuyos padres aparecieron asociados a las partículas señaladas. Por último, agrupamos a todas las personas para las cuales no se especificó estatus socioétnico o no pudimos suponerlo.

Para cotejar la información recogida en el Cuadro 1, contamos con la descripción que hizo el cura Villafañe en un informe presentado en 1736 al obispo de Tucumán, sobre la situación del curato de Belén, al que Santa María pertenecía como vice-parroquia: “...en el dicho Santa María se hallan algunas vecindades de gentes españolas, india y mestiza, aunque no hay pueblo de indios porque los que residen son agregados y conchavados y le parece por las confesiones que hizo que habrá adultos y de confesión de continua residencia ciento cincuenta personas, y que los vecinos españoles será siete y ocho"6.

Según este religioso, la población se constituía mayormente por indios y mestizos, y los españoles eran, claramente, una minoría. El informe de Villafañe confirma la tendencia que observamos a partir del Libro de Fábricas de Entierros. Entonces, ¿fueron correctos los criterios de clasificación elegidos por nosotros? ¿Nos acercan verdaderamente a la composición socio-étnica de la población de Santa María o, al menos, a la percepción que la sociedad tiene de sí misma? Sabemos, en el caso de los indígenas, que el hecho de considerar a los hijos con el mismo estatus del padre o de la madre podría esconder posibles matrimonios interétnicos o estrategias implementadas para cambiar el estatus socio-étnico del niño. Por su parte, si bien varios autores han señalado que la asociación de las palabras don, doña, sargento o capitán con la categoría de "español" ha sido evidente en varios lugares de la América colonial, es necesario preguntarnos si tales palabras son en todos los casos sinónimos de ser españoles. Asimismo, en el informe citado se introduce una categoría socio-étnica que no había aparecido hasta el momento: la de los mestizos. ¿Podemos considerar que todos aquellos que no fueron identificados con precisión por el mayordomo eclesiástico eran en realidad mestizos?

Autos sobre el valor y distancias del curato de Belén, en Larrouy y Soria (xxvi). 
Las dudas en relación con los criterios de clasificación son muchas. Como estrategia metodológica para reflexionar acerca de la composición poblacional y las categorizaciones socio-étnicas, seguiremos adelante con los criterios seleccionados, para luego, con base en la triangulación de datos y un análisis procesual, ponerlos en tensión. Para tal fin avanzaremos en el tiempo, para ver con qué otra información contamos.

Para la segunda mitad del siglo XVIII el estudio de los registros vitales, como defunciones y bautismos, aun si tomamos períodos diferentes (defunciones 17611793 y bautismos 1780-1792, según la documentación disponible en el APSM) para comparar, muestran tendencias muy similares entre sí. Con base en la utilización de los mismos criterios de clasificación señalados anteriormente, hemos elaborado los siguientes cuadros:

\section{Cuadro 2: Composicion socio-étnica según defunciones} (1761-1793)

\begin{tabular}{|l|c|c|c|c|c|c|}
\hline \multirow{2}{*}{$\begin{array}{c}\text { Defun- } \\
\text { ciones }\end{array}$} & \multicolumn{6}{|c|}{ Estatus socio-étnico } \\
\cline { 2 - 7 } & Español & Indio & Mestizo & Esclavo & Pardo Libre & Sin ident. \\
\hline Cant. & 192 & 143 & 10 & 13 & 4 & 119 \\
\hline$\%$ & 39,91 & 29,72 & 2,07 & 2,70 & 0,87 & 24,74 \\
\hline
\end{tabular}

Fuente: Elaboración propia, con base en APSM: Libro Casados 1A; Libro II Defunciones (Actas de Defunciones) y Libro I Bautismos.

\section{Cuadro 3: Composición socio-étnica según bautismos (1780-1792)}

\begin{tabular}{|l|c|c|c|c|c|c|}
\hline \multirow{2}{*}{$\begin{array}{c}\text { Bautis- } \\
\text { mos }\end{array}$} & \multicolumn{7}{|c|}{ Estatus socio-étnico } \\
\cline { 2 - 7 } & Español & Indio & Mestizo & Esclavo & Pardo Libre & Sin ident. \\
\hline Cant. & 162 & 173 & 20 & 5 & 9 & 138 \\
\hline$\%$ & 31,95 & 34,12 & 3,94 & 0,98 & 1,77 & 27,21 \\
\hline
\end{tabular}

Fuente: Elaboración propia, con base en APSM: Libro I Bautismos (Actas de Bautismos).

Si recordamos que las inscripciones de los registros vitales se hacían en libros separados, Libro de Españoles, por un lado, y Libro de Naturales, por otro (que incluía indios, mestizos, esclavos y castas en general, además de los que hemos englobado en "sin clasificar"), podemos afirmar que a fines del siglo XVIII los españoles aún eran una minoría en Santa María, y que los naturales constituían la mayoría. Ahora bien, si comparamos estos datos con aquellos con los que disponemos para la primera mitad de siglo observamos que la cantidad de españoles creció notablemente y que se emparejó con la cantidad de personas que fueron clasificadas como indígenas. Un dato para agregar es que hacia la segunda mitad del siglo XVIII emergen otras categorías que apenas si habían aparecido a principios de siglo. Me refiero a los esclavos, a los mestizos y a los pardos libres, que, 
de todas maneras, constituyen una porción menor de la población. Asimismo, es indispensable llamar la atención sobre la gran cantidad de personas que no fueron designadas bajo ningún rótulo socio-étnico. Si bien —entre los primeros años del siglo y la segunda mitad - la proporción de gente "sin identificación" disminuyó, igualmente la cifra siguió siendo muy elevada.

Retomemos ahora algunas de las preguntas y dudas planteadas hasta el momento en cuanto a las clasificaciones socio-étnicas, pero a partir del análisis del único registro general de población disponible para el siglo XVIII: el censo de $1771^{7}$. Este censo presenta dificultades para analizar la composición socio-étnica. Las personas fueron censadas en 30 unidades, a la cabeza de las cuales se ubicaba generalmente un don o doña que nucleaba una población heterogénea, clasificada en algunos casos según estatus socio-étnico; en otros, según estatus laboral, y en otros, directamente no identificada. Según nuestras estimaciones, la población de Santa María ascendía a 917 personas. A continuación, una síntesis de los datos recogidos a partir del censo y elaborada según los mismos criterios antes reseñados. Asimismo, incorporamos las estimaciones de Beatriz Rasini, no solo porque es la única autora que ha analizado dicho censo exclusivamente para nuestro espacio de estudio ${ }^{8}$ (y, en ese sentido, una referencia insoslayable), sino en tanto que su análisis nos permite introducir algunas discusiones sobre el tema de las clasificaciones étnicas.

\section{Cuadro 4: Composición socio-étnica según Censo de 1771}

\begin{tabular}{|c|c|c|c|c|c|c|c|c|c|c|c|}
\hline \multicolumn{10}{|c|}{ Estatus étnico } \\
\hline \multicolumn{2}{|c|}{ Indios } & \multicolumn{2}{|c|}{ Españoles } & \multicolumn{2}{c|}{ Mestizos } & \multicolumn{2}{|c|}{ Esclavos } & \multicolumn{2}{|c|}{ Libres } & \multicolumn{2}{|c|}{ Sin ident. } \\
\hline Cant. & $\%$ & Cant. & $\%$ & Cant. & $\%$ & Cant. & $\%$ & Cant. & $\%$ & Cant. & $\%$ \\
\hline 345 & 38 & 151 & 16,4 & 16 & 1,75 & 8 & 0,9 & 18 & 2 & 375 & 41 \\
\hline
\end{tabular}

Fuente: Elaboración propia, con base en el Censo de 1771 (Acevedo).

Este censo fue realizado por pedido de Carlos III para determinar la cantidad de población, los curatos y el número de sacerdotes de la jurisdicción catamarqueña, y decidir si era o no necesario erigir un convento de mercedarios en la ciudad que atendieran las almas de los fieles (Acevedo).

8 Otra autora que ha trabajado parcialmente el censo del 71 es De la Orden. Sus estimaciones respecto a la población indígena coinciden con las cifras manejadas por Rasini y por nosotros. No podemos avanzar en la comparación, pues dicha autora contabilizó solo a la población indígena y no explicitó los criterios de clasificación utilizados. 
Cuadro 5: Composición socio-étnica según Censo de 1771; Rasini (1962/3)

\begin{tabular}{|c|c|c|c|c|c|c|c|c|c|}
\hline \multicolumn{7}{|c|}{ Estatus socio-étnico } \\
\hline \multicolumn{2}{|c|}{ Indios } & \multicolumn{2}{|c|}{ Blancos } & \multicolumn{2}{c|}{ Mestizos } & \multicolumn{2}{c|}{ Negros } & \multicolumn{2}{c|}{ Mulatos y pardos } \\
\hline Cant. & $\%$ & Cant. & $\%$ & Cant. & $\%$ & Cant. & $\%$ & Cant. & $\%$ \\
\hline 356 & 38,9 & 151 & 16,5 & 368 & 40,3 & 16 & 1,8 & 23 & 2,5 \\
\hline
\end{tabular}

Fuente: Elaboración propia.

Si comparamos los cuadros, notamos que el porcentaje de indios es similar en los dos casos. Sabemos que Rasini ha elegido el mismo criterio de clasificación que nosotros para contabilizar a los indios. Respecto a los datos recogidos del APSM, si bien el porcentaje del censo es algo superior en relación con la población clasificada como indígena, la comparación evidencia valores bastante parejos.

En relación con la contabilización que hicimos de aquellos a quienes clasificamos como españoles, y Rasini, como blancos, debemos decir que las cifras coinciden exactamente, aunque, como veremos luego, las mismas deben considerarse provisorias. No coinciden con las de Rasini las proporciones de negros, mulatos y pardos (libres y esclavos). En nuestro caso, hemos diferenciado a los esclavos (mayormente negros, aunque también se han registrado mulatos) de los que llamamos castas libres (fundamentalmente pardos, aunque también fueron asentados mulatos). Rasini ha preferido categorizar a negros por un lado y a mulatos y pardos por otro. No sabemos en cada uno de estos casos si tal diferenciación incorporaba tanto a los esclavos como a los libres, o si para la autora los negros estaban asociados a la esclavitud y las castas señaladas al estatus de libres. De todas maneras, más allá de los criterios empleados y las distintas cifras alcanzadas, es evidente que tanto la población esclava como las castas libres constituían una ínfima proporción de la población total.

Existe, sin embargo, un criterio de clasificación empleado por Rasini que merece ser discutido. Tal como se observa en el cuadro que recoge nuestros cálculos, hemos contabilizado a 16 personas registradas bajo la categoría de mestizos, mientras que para Rasini ascendieron a 368 (más del 40\% de la población total). ¿Cuál fue el parámetro tomado por esta autora? Al respecto, ella dice: "Por eliminación, hemos considerado al resto mestizos. Es decir, incluimos como tales a los que no aparecen en ninguno de los otros grupos. En muy pocos casos (16 en total) se encuentra concretamente especificada la condición mestiza"(48). O sea que aquellos a los que no se les asignó una clasificación socio-étnica fueron considerados por Rasini como mestizos. Si bien esta es una posible aproximación a la interpretación de los datos, consideramos que, por el momento, es más ajustado 
diferenciar a los mestizos de los “sin identificación”, por dos razones, básicamente. Por un lado, la categoría de mestizo no solo aparece en una baja frecuencia en el censo, sino también en los registros parroquiales. Por otro lado, si cruzamos los datos del censo con los del archivo parroquial, observamos que una cantidad importante de personas a las que no se les asignó una clasificación socio-étnica en el censo de 1771 fueron asentados en el Libro de Españoles en uno o varios momentos a lo largo de sus vidas, y nunca se los calificó directamente como mestizos en tales libros. Un ejemplo en ese sentido es el de Juana Arias, a quien durante el censo no se la asoció a ningún estatus socio-étnico ni se le agregó la partícula de doña. Sabemos, sin embargo, que a lo largo de su vida fue registrada varias veces en el Libro de Españoles. En 1780 Juana Arias y su esposo, Ventura Cortés, fueron asentados como padres de Josefa Cortés, quien estaba contrayendo matrimonio con Juan Francisco Iturre (APSM, Libro I Bautismos. Casamiento de españoles. f. 28v). En 1786 Juana Arias — ahora calificada como doña—aparecía en el acta de matrimonio de su hijo don Santiago Cortés, quien estaba casándose con doña María Rueda (APSM, Libro I Bautismos. Casamiento de españoles. f. 31v). En 1789 doña Juana Arias Velásquez era registrada en el acta de matrimonio de su hijo don Juan Cortés con doña Ambrosia Dávila (APSM, Libro I Bautismos. Casamiento de españoles. f. 33r). Finalmente, disponemos de la defunción de doña Juana Arias viuda de don Ventura Cortés, que fue asentada el 7 de marzo de 1792, también en el Libro de Españoles (APSM, Libro I Bautismos. Entierros de españoles. f. 62r).

Este "descubrimiento" nos lleva a hacernos algunos replanteos metodológicos. En primer lugar, nos impulsa a revisar el criterio de clasificación que empleamos cuando entendimos que solo aquellos que llevaban la partícula don o doña eran considerados como españoles. La comparación del censo de 1771 con los registros parroquiales nos muestra que el uso de tales partículas no es un criterio totalmente válido para conocer la cantidad de individuos considerados como españoles en Santa María. Las actas parroquiales nos muestran que las personas podían ser consideradas "españolas" y, por ende, ser registradas en tal Libro sin necesidad de ser dones, y que, además, esta condición podía ir cambiando a lo largo de la vida.

Por otro lado, reflexionando sobre el precepto de Rasini de considerar como mestizas a las personas que no tuvieron identificación en el censo de 1771, y que nosotros hemos rastreado en el Libro de Españoles, nos preguntamos: $i$ el hecho de ser registrados en tal libro significaba que estas personas y sus antepasados no habían incurrido en ningún tipo de mestizajes o mezclas? La respuesta que, por ahora, daremos a esta pregunta es que, más allá de que estas personas fueran - tal como hoy lo entenderíamos - mestizos strictu sensu, no fueron diferenciadas como tales y, por lo tanto, parece un error encasillarlas bajo el rótulo de mestizos. 
Volveremos sobre el asunto en el apartado siguiente, donde analizaremos el significado de algunos de los estatus socio-étnicos, la forma como fueron variando a lo largo del tiempo y los usos locales o particulares que encontramos de los mismos en el contexto de la Santa María dieciochesca.

\section{Desbrozando algunas categorías socio-étnicas}

En el apartado anterior vimos que el criterio de considerar como españoles solo a aquellos con la designación de don o doña resultaba un tanto engañoso. Muchas personas sin la adición de esas partículas fueron inscriptas en el Libro de Españoles, y, por lo tanto, considerados como tales. Así, en Santa María los españoles resultaban ser un "grupo" heterogéneo que incluía tanto a descendientes de tradicionales familias de conquistadores como a algunos peninsulares de llegada más reciente, e, igualmente, a un conjunto variado de personas, probablemente de menores recursos y escasos vínculos con los más acomodados.

Desde que comenzamos a analizar los datos del APSM nos llamó la atención la poca cantidad de personas clasificadas como mestizas. Al principio suponíamos que la población de Santa María habría estado constituida por una cantidad mayoritaria de personas calificadas con tal estatus. ¿Cómo explicamos, sin embargo, el bajo porcentaje que arrojan los datos de la parroquia, así como el censo de 1771 ¿Es que efectivamente no se dieron procesos de mestizaje en la zona? La respuesta a estas preguntas se divide en dos partes. Por un lado, proponemos la hipótesis de que la "sociedad santamariana" - especialmente en su etapa formativa - absorbió a buena parte de los mestizos dentro de la categoría de españoles; esto es: los reconoció como tales ${ }^{9}$. Esto explicaría, a su vez, el incremento de la población española que observamos al comparar los registros vitales de los primeros años del siglo XVIII con aquellos de la segunda mitad. Por otro lado, la aparición de un número creciente de mestizos hacia el último tercio del siglo XVIII - ahora inscriptos en los Libros de Naturales - no sería indicador de que los santamarianos estaban "mezclándose" más hacia fin de siglo, sino que los criterios de clasificación estaban cambiando, justamente, para impedir los pases de categoría. Paradójicamente, la estructura social de Santa María iba haciéndose más rígida y jerarquizada cuando la sociedad estamental llegaba a su ocaso.

9 Ya Lockhart (1990) había señalado que el análisis de distintos registros censales u otro tipo de información demográfica ha mostrado una cantidad inferior a la esperada de mestizos. El hecho fue explicado por este autor considerando - tal como lo refleja nuestro caso - que parte de los mismos fueron visualizados por sus contemporáneos directamente como españoles. En particular, dice Lockhart, esta situación se dio en lugares periféricos, donde había unos pocos españoles entre una gran cantidad de indios, o bien en períodos de formación de la sociedad local con imperiosas necesidades de engrosar las filas de "españoles", con el fin de cimentar el entramado local de poder y privilegios. 
Ahora bien, ¿con qué datos contamos para apoyar tales interpretaciones? Respecto al primer punto, resulta útil hacer algunas comparaciones con el censo de $1812^{10}$. Muchos de los que fueron inscriptos en el Libro de Españoles hasta fines del siglo anterior fueron registrados como mestizos en dicho censo. Uno de los casos para los que tenemos mayor información es el de la familia Saciega. Clemente Saciega apareció por primera vez en nuestros documentos en el censo del año 1771. Allí fue registrado junto a su esposa Calixta Arabena, dos hijas y la familia política, como parte de una unidad productiva más amplia. En ese momento ni él ni sus parientes fueron identificados con designación socio-étnica alguna, ni se les agregó la partícula de don. Esta falta de precisión en el censo no impidió que Clemente y su familia aparecieran varias veces inscriptos en los libros parroquiales en la sección de los españoles. Desde 1780 Clemente y su nueva esposa -Felipa González- aparecieron siempre en el Libro de Españoles, ya sea bautizando o enterrando a sus hijos y, por lo general, asociados a las partículas de don y doña ${ }^{11}$. En el censo de 1812, sin embargo, si bien Clemente continuó siendo calificado de don e inscripto bajo la "clase" de español, tanto su esposa como sus hijos (los de ambos matrimonios) fueron registrados como mestizos ${ }^{12}$.

Es posible que este ejemplo sólo sea reflejo de distintos criterios de clasificación empleados por curas y censista, como consecuencia del descuido de quienes hicieron las inscripciones o fruto del azar. Y es cierto, también, que hemos

10 Este censo, dispuesto por el Primer Triunvirato, estuvo destinado a la totalidad de las Provincias Unidas del Río de la Plata, y tuvo como fin conocer a la población en condiciones de incorporarse a las filas militares en los albores de la Independencia. En el caso de Santa María, el censo está integrado por dos padrones; uno llevado a cabo por el capitán Carlos Villagra y el otro, por el capitán Ubaldo Córdoba.

11 En 1782 Clemente y Felipa bautizaron a María Narcisa; en 1784 los ahora don Clemente y doña Felipa bautizaron a Francisca Paula; en 1786, a José Patricio; en 1787, a María Toribia; en 1790, a María Genuaria, y en 1793, a Ana María (APSM Libro I Bautismos, Actas de Bautismos de Españoles, fs. 2r, 7v, 12v, 14v, 18r y 23r). Asimismo, las hijas mayores de don Clemente y de Calixta Arabena también registraron los bautismos de varios de sus niños: en 1784 el de Isidoro, hijo natural de Gertrudis Saciega; en 1786, el de María Hilaria, hija legítima de María Mercedes Saciega y Lorenzo Rueda; en 1788, el de José Casimiro, hijo de la pareja anterior, y el de Cayetano, hijo natural de Gertrudis Sacieda, y en 1792, el de José Gabriel, hijo de don Lorenzo Rueda y doña Mercedes Saciega (APSM Libro I Bautismos, Actas de Bautismos de Españoles, fs. 9r, 13r, 15r, 17v y 21v). Tenemos también registro de los casamientos de las hijas mayores de don Clemente: en 1786 el de doña María Mercedes Saciega con don Lorenzo Rueda; en 1789, el de Gertrudis Saciega con Ambrocio Monasterio, y en 1793, el de doña Felipa Saciega (hija adoptiva de don Clemente y doña Felipa) con don Marcelo Aguilera (APSM Libro I Bautismos, Actas de Casamientos de Españoles, fs. 31r, 33r, y 36v). Por último, tenemos registro del fallecimiento de varios de hijos de Clemente y Felipa: en 1780, José María; en 1784, María Narcisa; en 1786, José Patricio. También el fallecimiento de María Hilaria, hija de Lorenzo Rueda y María Mercedes Saciega (APSM Libro I Bautismos, Actas de Defunciones de Españoles, fs. $49 \mathrm{v}, 50 \mathrm{v}, 55 \mathrm{v}$ y $57 \mathrm{v}$ ).

12 Censo de 1812, transcripción en Ruggeroni (78, 80, 86 y 87). 
comprobado la laxitud con la que se hacían algunas inscripciones parroquiales, a pesar de la insistencia de los visitadores eclesiásticos. Sin embargo, creemos - a la luz de los casos similares que hemos encontrado- que tales cambios de estatus 0 , en realidad, de las percepciones acerca de la "calidad" de los personas no fueron azarosos. El quid es saber con base en qué características fueron categorizados los integrantes de dicha familia en los distintos momentos. Castillo Palma ha señalado que la calificación de las personas dependía en cada momento y lugar de la particular relación que se establecía entre tres factores: ascendencia, atributos socio-culturales y apariencia física. Siguiendo a esta autora, podríamos aventurar que mientras durante buena parte del siglo XVIII los factores que más pesaron para definir el estatus de una persona fueron la ascendencia o los atributos socio-culturales, hacia fines de ese siglo y principios del siguiente el peso comenzó a recaer lentamente sobre la apariencia física. Para el caso de la familia Saciega, el ascendiente que había permitido a hijos (y agregaríamos que a esposa) ser considerados como españoles seguía siendo el mismo a principios del siglo XIX: don Clemente, oriundo del Cuzco e hijo legítimo de don Ramón Saciega y de doña Juana Chávez. Los atributos socio-culturales de esta familia también se habían mantenido. Según el testamento de don Clemente, e incluso el de uno de sus hijos (AHC, Causa Civil, Sección S, Caja 27, Dto. Santa María, Expte. 1154, Año 1823; Actor: Saciega, Clemente; Concepto: sucesorio. AHC, Libro de Protocolos n ${ }^{\circ}$ 44, Año 1849, Testamento de Rosario Saciega. Fs. 37v a 39r), los Saciega seguían siendo una familia acomodada, con varias propiedades y, sobre todo, vinculada comercial y familiarmente con la élite de Santa María. Por lo tanto, considerando que tales factores no se habían modificado, es posible que hacia el cambio de siglo empezaran a tener importancia ciertos rasgos fenotípicos para definir las calidades de las personas, que hasta el momento no habían sido definitorios. Esto nos lleva, entonces, a retomar el segundo de los puntos que hemos dejado sin responder: el cambio de los criterios de clasificación.

El punto que intento demostrar es que el fenómeno del mestizaje se dio mucho antes de que encontráramos mestizos en los documentos. Hasta la década de 1770 (cuando empiezan a registrarse mestizos en un número creciente dentro de la población) y dependiendo de los factores definitorios antes señalados, los mestizos fueron o bien asimilados a la categoría de español o bien categorizados directamente como indígenas (en el mejor de los casos no les asignó una clasificación étnica). Durante la mayor parte del siglo XVIII los mestizos no fueron marcados como tales, y pudieron en muchos casos traspasar las fronteras étnicas y sociales. Hacia el último tercio del siglo, en parte quizás como consecuencia de las políticas borbónicas para controlar mejor a la población, los mestizos empezaron a ser señalados más estrictamente, pero ahora, incorporados al mundo de los "naturales". De hecho, algunos párrocos comenzaron a poner en duda las calidades de quienes recibían algún sacramento en la parroquia. Un caso interesante es el 
de José Julián Monasterio y su esposa, María Rueda. Ambos personajes y sus respectivas familias siempre fueron inscriptos en el Libro de Españoles, y en muchos casos con las partículas de dones y doñas. En el año 1794, en cambio, en la inscripción de la defunción de una hija de aquel matrimonio, el cura anotó que los padres "corren por españoles" (APSM, Libro Casados 1A, Partidas de finados de todas las clases de la vice-parroquia de San José. F. 13r); es decir, que no fueron anotados directamente como tales. Creemos ver en esta fórmula un indicativo de la duda del párroco acerca de la calidad de estas personas. Si hacemos la prueba de observar cómo fueron clasificados en el censo de 1812, vemos que el censista los registró a ambos como mestizos (Ruggeroni 102). A su vez, en 1813, en el bautismo de otra hija de la pareja, aunque no se les asignó a ninguno de ellos una categoría socio-étnica precisa, el acta fue inscripta en el Libro de Naturales (APSM, Libro II de Bautismos 1813-1817, F. 98r.).

Un cambio en la organización de los libros parroquiales apoya la interpretación de que hacia fines del XVIII los criterios clasificatorios estaban haciéndose más estrictos. El primer libro de la iglesia con que contamos (APSM, Casados 1A 1761-1779) destinado a la inscripción de las defunciones fue dividido — al igual que los demás - en dos: españoles por un lado y naturales por otro. Sin embargo, en el de naturales se agregó: "Partidas de entierro de indios, mulatos y esclavos"; es decir, allí no fueron contemplados los mestizos (pues, como vimos, creemos que habrían sido incorporados al Libro de Españoles). De hecho, no se registró a nadie bajo este rótulo. Los libros siguientes respetaron esa gran división, pero a partir de aquellos iniciados entre 1777-1780 (APSM) ${ }^{13}$ empezó a inscribirse a algunos mestizos dentro del Libro de Naturales para incrementarse definitivamente su proporción a partir del siglo XIX.

Ahora bien, el fenómeno del mestizaje no solo estaba asociado a la categoría de mestizo, cuya primera y estricta definición hace referencia a descendientes de españoles e indios. Para el mismo momento en que aparecía justamente aquella categoría en el APSM, también vemos que empiezan a registrarse algunos pardos (por lo general libres) y unos pocos mulatos, también fruto de las mezclas, aunque vinculados con ascendientes de origen africano. A diferencia de los propiamente mestizos, pardos y mulatos difícilmente fueron incorporados al "mundo español". Si bien en el primer libro del APSM disponible no se asentaron personas con tales categorías, el hecho de que el mismo fuera rotulado como "Partidas de entierro de indios, mulatos y esclavos" es indicativo de que el lugar que a ellos les estaba reservado era junto a los indios y esclavos. Otro dato para agregar es

13 El año de inicio depende de cada sacramento. Mientras casamientos y defunciones se inician en 1777, los bautismos lo hacen en 1780 . 
que, al menos hasta fines del siglo XVIII, pardos y mulatos, si bien lograron en algunos casos que el párroco no los anotara con una identificación étnica precisa, por lo general mantuvieron dicho estatus a lo largo del tiempo.

El análisis de censo de 1812 es interesante, pues nos habla de otra clasificación socio-étnica resultado de las mezclas, y que hasta el momento no había aparecido: los cholos. La emergencia de este nuevo estatus en el contexto santamariano de las postrimerías de la colonia, seguramente, apuntaba a diferenciar aún más a la población. Saignes (1990) ha definido al cholo colonial como "un mestizo en hábito de indios". Si tal definición fuera aplicable al caso de los cholos en Santa María, entonces es entendible que el empadronador encontrara indispensable distinguirlos de los mestizos (muchos de los cuales habían sido anotados como españoles en las actas parroquiales). Una cosa era ser un "mestizo en hábito de español" y otra muy distinta, ser un "mestizo en hábito de indios".

A diferencia de estas últimas categorías que acabamos de analizar, el estatus de indio apareció tempranamente en los registros de la parroquia. En el valle de Santa María los indios fueron marcados como tales desde la primeras entradas hasta fines del período colonial (y aún más allá de él). Ahora bien, ¿era lo mismo ser un indio en Santa María a fines del siglo XVII que a fines del XVIII? Por supuesto que no, pues la categoría fue haciéndose cada vez más compleja y adquiriendo nuevos significados a lo largo del tiempo.

A principios del siglo XVIII los registros parroquiales que transcribió el padre Larrouy nos muestran una mayoritaria población de indios, aunque no tenemos datos acerca de quiénes son específicamente, pues solo figura su nombre de pila, o bien que son del servicio de alguien o pertenecen a tal o cual personaje. Así, por ejemplo, el capitán don Pablo Palacio aparece en reiteradas oportunidades pagando los gastos de entierro de indios de "su servicio": "don Pablo Palacio pagó 4 ps de india de su servicio"; "don Pablo Palacio pagó 4 ps de un hijo de su india" (Larrouy).

Hasta la mitad del siglo, debido en parte al tipo de fuente de que disponemos (básicamente, las Fábricas de Entierros), los registros no nos legan mucha información en cuanto a la población indígena. En algunos pocos casos se registraron los lugares de origen o la pertenencia a grupo étnico. Así, por ejemplo, en 1738 se anotó en el Libro de Fábrica la defunción de Ignacia Mocoví; en 1744, la de Pascual Atacama, y en 1745, la de Antonio, hijo de Francisco Ingamana (Larrouy). Estos datos fragmentarios, sin embargo, van ayudándonos a percibir el complejo panorama socio-étnico y, en especial, a comprender la heterogeneidad que abarca el estatus de indio en dicho contexto, aspecto que se complejizará aún más a medida que avancemos en el tiempo. 
Hacia la segunda mitad del siglo, ya a partir del análisis de las Actas Parroquiales, la información empieza a tornarse más completa. En primer lugar, los indios se registran con nombre y apellido. Lamentablemente, para esta época el uso de los apellidos como indicador de "indianidad" ya no es útil, pues buena parte de los indios en Santa María ya poseen un apellido español; sin embargo, este dato resulta útil para realizar un análisis de tipo nominativo de la población. Se agregan también otros datos como parentesco o edades, y lentamente deja de usarse la fórmula de "indio del servicio de" o "indio de", que continúa aplicándose solo en el caso de los "indios esclavos".

En el APSM hemos observado algunos casos de este tipo. Así, por ejemplo, encontramos registrada la muerte de Melchor en 1784, cuando tenía 11 años, quien aparece como "indio y esclavo" de doña Juana Arias, o la de Valeriana Cansinos, muerta en 1786 a los 16 años, e hija natural de Rosa Cansinos, que aparecen como "indias esclavas" de don Basilio Cansinos (APSM, Libro I Bautismos, Entierro de Naturales. Fs. 132v y 138v). Tal como lo ha señalado Zavala (1994), una de las causas por las cuales se podía esclavizar a los indios era la denominada "guerra justa", la cual implicaba que aquellos indios que se negaran a ser vasallos de la Corona y fueran vencidos en combate serían capturados y esclavizados. Este debió de ser el caso de los indios esclavos que encontramos en Santa María, seguramente provenientes de la frontera oriental, capturados y repartidos por grupos a los distintos beneméritos participantes de las entradas al Chaco. Hemos encontrado registros de mocovíes en los papeles de la parroquia, y creemos que este podría ser el origen de muchos de los indios esclavos que fueron registrados. Tenemos también noticias de que algunos personajes importantes de Santa María participaron de las expediciones citadas. Por ejemplo, en el año 1740 no se realizaron las elecciones de las autoridades de la Cofradía de Españoles "por ausencia del capitán don Francisco de Villagra, Mayordomo Mayor, que fue a la entrada contra el bárbaro enemigo" (Manuscrito Larrouy). Otra posibilidad de obtener indios esclavos parece haber sido la compra. En el inventario de los bienes de Gerónimo Álvarez, realizado en el año 1756, se detalla entre los bienes del difunto a dos indias mocovíes compradas: una de 18 años y la otra ya grande (madre de la anterior), así como un indio criollo mocoví (AHC, Sección C, Causa Civil, Caja 6, Depto. Santa María, expediente 249, año 1756, f. 22v).

Por otro lado, a medida que transcurren los años, en las actas parroquiales empiezan a hacerse algunas distinciones dentro del estatus de indio. A la categoría de indio, que en muchas oportunidades aparece a secas, van sumándose la de indio libre y la de indio de la encomienda de o indio tributario de. Para estos últimos casos, encontramos ejemplos de indios tributarios de Amaicha, del Curato de los Molinos, aunque también se han relevado indios tributarios de lugares más leja- 
nos, como de la Rinconada, y especialmente, indios tributarios de Atacama. La situación de estos indios era variada y venía mutando desde mediados del siglo XVIII. Como ha señalado Punta (1994) — analizando el caso de Córdoba - , hacia esa fecha se inició el proceso de pasaje del sistema de encomiendas privadas al sistema de pago del tributo directamente a la Corona. Si bien, en líneas generales, esto es cierto para todo el Tucumán, en jurisdicciones como la catamarqueña o tucumana, tal proceso pudo haber sido más lento, pues ya casi finalizado el siglo aún había indios de encomienda ${ }^{14}$.

Lo cierto es que el ser marcados no solo como indios, sino también como tributarios en los registros parroquiales, era de vital importancia para la Corona, pues estas inscripciones habrían servido como fuente para cobrar los tributos o manejar la fuerza de trabajo indígena. De hecho, en las revisitas de indios que se realizaron hacia fines del siglo XVIII debían estar presentes los curas para exhibir los libros de bautismos, defunciones y matrimonios, y así poder cotejar la información.

Ahora bien, la mayor parte de los indios fueron registrados como indios o indios libres. A diferencia de los anteriores, estas personas no estaban atadas a una encomienda. Es decir, aunque fueron diferenciados étnica o socialmente bajo el estatus de indio, fiscalmente no poseían la categoría de tributarios, estaban exentos del pago del tributo. Como ha señalado Gil Montero (2006), es muy difícil hacer un seguimiento de este tipo de indígenas, pues la mayor parte de la documentación elaborada por la Corona está referida a la población tributaria. En este sentido, es interesante notar el desfase que existe en cuanto a la cantidad de población indígena si comparamos los datos del APSM de fines del siglo XVIII con las revisitas de indios que se realizaron para la misma época ${ }^{15}$.

Como hemos señalado, las revisitas realizadas hacia fines del período colonial tenían como fin hacer un recuento de la población indígena tributaria. Para Santa María solo contamos con la de 1792 (AGN, Sala XIII, 17-2-1. Colonia Contaduría), en la que se registraron los "forasteros sin tierras asistentes" en dicha doctri-

14 En 1786 había en la jurisdicción catamarqueña 18 pueblos de indios (nueve en cabeza de su majestad y nueve en manos privadas), con 116 tributarios (de la Orden 2005). En 1792 eran tributarios de la Corona 199 indios y 101 dependían de encomiendas privadas (AGNA, Sala XIII, 17-2-1. Colonia Contaduría, 1792). En Tucumán, del total de indios censados, todavía el $50 \%$ en 1786 y el $18 \%$ en 1792 estaban sujetos a la encomienda de servicio personal. Incluso, en 1806 aún sobrevivía el pueblo de Belicha, encomendado a don Miguel de Medina, quien lo gozaba en tercera vida (López de Albornoz 1996, 2003).

15 Este mismo desfase puede observarse si se comparan las cifras de las revisitas de indios de 1786 y 1792 (que solo contabilizaron a la población tributaria) con las del recuento de 1778 (que incluyeron a toda la población clasificada como indígena). Así, mientras que en la revisita de Catamarca de 1786 fueron inscriptos 1.182 indios, en el censo de 1778 la jurisdicción catamarqueña contaba con 2.817 . 
na, más un padrón de tributarios atacameños, también anotados como forasteros sin tierras, realizado aparte del resto por petición de uno de los curas de Calchaquí $^{16}$. Las familias allí inscriptas ascendieron a 37, en su mayoría atacamas. Si cruzamos la información de la revisita con los datos del APSM, aun cuando lo hagamos solo con los del año 1792, observamos que hay indios (en su mayoría libres) inscriptos en el APSM que no figuraron en el padrón.

Además del problema del heterogéneo estatus de indio que observamos tanto en las revisitas como en los registros parroquiales, debemos insistir en la labilidad de las categorizaciones y en la variabilidad de criterios para clasificar a las personas y, ¿por qué no?, también, en la posibilidad de pensar que tales clasificaciones eran negociables y, por lo tanto, muy móviles y flexibles. Sumariamente, ya hemos trabajado estos temas en el apartado anterior, en el que señalamos no solo los criterios diferentes de curas o censistas, sino, también, los de los propios investigadores, así como los cambios de estatus de una misma persona a lo largo de su vida. Quisiéramos retomar dichos aspectos, pero aplicándolos al caso específico de los indígenas y desarrollándolos a partir de un análisis cualitativo desprendido de algunos ejemplos.

En primer lugar, hay que señalar que muchos de quienes fueron empadronados en la revisita de 1792 figuraron como indios libres en el APSM. Por ejemplo, Juan Chávez, registrado en la revisita de Catamarca como indio forastero de Santa Cruz de la Sierra, casado con María Santos Gutiérrez (AGN, Sala XIII, 17-2-1, Revisita de Catamarca, año 1792. F. 52v), había sido registrado en 1788 en su casamiento como indio libre, al igual que en 1789, en el bautismo de un hijo de la pareja (APSM, Libro I Bautismos. Casamientos de Naturales, f. 115v. Bautismos de Naturales, f. 102r). En segundo lugar, las inscripciones parroquiales no solo no coinciden con las clasificaciones de los distintos censos o padrones, sino que tampoco parecen concordar internamente (aun cuando fue el mismo cura quien hizo las inscripciones). El desarrollo de un ejemplo puede ser ilustrativo. El primer registro que tenemos sobre Clemente Caliba y Ventura Cáceres es el del censo de 1771, en el que Clemente fue calificado por el censista como indio (Acevedo 66). En 1774 dicha pareja apareció por primera vez en el APSM cuando enterraron a su hijo Antonio. Aunque el acta se inscribió en el Libro de Naturales, el cura no especificó a qué categoría socio-étnica pertenecían los padres o el niño fallecido. En 1782 Clemente y Ventura, aparecieron en el Libro de Naturales bautizando a una niña llamada María Paula. Allí todos fueron inscriptos como indios libres.

16 En 1791 el cura de Calchaquí pidió al Gobernador Intendente de Salta que los indios atacamas residentes en Calchaquí fuesen empadronados y pagaran sus tributos allí. De esta forma, el cura se aseguraba el cobro del sínodo correspondiente (AGN, Sala IX, 30-4-9. Interior. Leg. 33 - expediente 33; Rodríguez). 
En 1784 bautizaron a otra hija, llamada Justa Pastora, y en esa ocasión ninguno recibió designación socio-étnica. En 1787, en cambio, otro hijo de la misma pareja - Manuel - fue inscripto como mestizo (APSM, Casados 1A, Partidas de entierros de Indios, Mulatos y Esclavos, F. 209v. Libro I Bautismos 1777-1794. Bautismos de Naturales, Fs. 69r, 76r y 89v). Por último, en el censo de 1812 todos los integrantes de la familia Caliba-Cáceres fueron designados como cholos (Ruggeroni 91).

El caso desarrollado resume lo dicho hasta el momento. Muestra las distintas formas como censistas y curas párrocos clasificaron a una misma población; evidencia lo difuso de los límites socio-étnicos y lo maleables que eran, a tal punto que una persona podía variar de estatus a lo largo de su vida. El caso elegido, al abarcar varios años en la vida de una familia, puede ser indicativo de los cambios ocurridos en los criterios mismos de clasificación socio-étnica; así, mientras en la década de 1770 una persona podía ser clasificada como india, en 1812 se registraba con una nueva categoría: la de chola.

En síntesis, la realidad santamariana finisecular nos muestra que ser indio no solo no significaba lo mismo que a fines del siglo XVII, sino que significaba varias cosas a la vez. En un principio, indio era quien residía como originario en su comunidad o pueblo de reducción. Luego indio fue también quien migrando se convirtió en forastero o logró el estatus de libre. Indios fueron también los que habiendo sido capturados en el Chaco o comprados se consideraron como esclavos. Como lo ha señalado Wachtel (2001), la nomenclatura de los padrones utilizó una terminología cada vez más heterogénea para clasificar a los indios (forasteros con tierras, forasteros sin tierras, originarios con tierras, originarios sin tierras, originarios asimilados a forasteros, sobrinos, yernos, legítimos...). Los registros parroquiales de Santa María también dan cuenta de esta complejidad, pero, en nuestro caso, la misma parece aún más intrincada, debido a la particular situación de la que hemos partido. Sin un pueblo de indios, la población indígena que fue asentándose en la zona tuvo diversos orígenes y estatus y se desarrolló de diversas maneras. A fines del período colonial los indios existían en nuestra zona, y en un número importante, aunque lo único que compartieran fuera el hecho mismo de ser considerados como indios.

\section{Balance y cierre}

A lo largo del artículo trabajamos dos aspectos: por un lado, avanzamos acerca de la composición socio-étnica de la población en estudio durante el siglo XVIII; por otro, discutimos los criterios de clasificación con base en los cuales curas, censistas e investigadores "etiquetaron" a la misma. 
En relación con el primer aspecto, los datos disponibles para las primeras décadas del siglo nos mostraron una composición esquemática de la población. Esto es, individuos clara y mayoritariamente demarcados como indios frente a una minoría de españoles. Esos primeros datos también reflejaron una importante cantidad de personas sin clasificación socio-étnica. Hacia la segunda mitad del siglo, si bien el panorama étnico continuó siendo dual, parece hacerse más complicado, pues fueron registradas otras categorías como las de esclavos, pardos y mulatos libres, y mestizos. De todas maneras, los indios - dentro del Libro de Naturales-constituyeron una clara mayoría, aunque para las últimas décadas del siglo XVIII la proporción de personas así calificadas se emparejó bastante con los que fueron registrados en los Libros de Españoles. Asimismo, la cantidad de personas que dentro del Libro de Naturales no obtuvieron una clasificación socio-étnica precisa siguió siendo bastante importante.

Sobre el segundo aspecto, y tal como ha quedado evidenciado, la discusión en torno a los criterios de clasificación socio-étnica de una población determinada es, por diversas razones, un tema sumamente complejo. Por un lado, porque no siempre conocemos en detalle los criterios que utilizaron quienes hicieron las clasificaciones (a veces, incluso, no queda claro quién es el clasificador); a este aspecto debemos sumar las confusiones que los investigadores agregamos al utilizar nuestros propios parámetros, muchas veces no explicitados. En segundo lugar, porque las categorías resultan ser muy flexibles y sus significados cambiantes, de acuerdo con cada contexto socio-histórico. La categoría de indio es ilustrativa al respecto. ¿Qué significa ser indio en Santa María a fines del siglo XVIII? ¿Quiénes son indios? Para ser clasificado como indio ya no funciona el parámetro fiscal. Si bien siguen existiendo los indios tributarios, ser indio en el siglo XVIII representa una categoría mucho más amplia y múltiple. Así, en Santa María encontramos una importante población de indios libres, hay indios esclavos y, fundamentalmente - dentro de los Libros de Naturales - hay muchas personas sin clasificación socio-étnica. Tal como lo ha expresado Barragán (2000), la categoría fiscal de indio (ya de por sí encubridora de heterogeneidades) fue entrecruzándose con la concepción de lo indio como categoría social, y, por lo tanto, haciendo más complejo su abordaje.

En síntesis, este trabajo ha sido un ejercicio para dar cuenta de la complejidad que implica abordar la composición y clasificación socio-étnica de las poblaciones y, en ese sentido, una invitación tanto a seguir reflexionando sobre estos temas, a la luz de las nuevas corrientes teórico-metodológicas, como a buscar y a triangular todo tipo de documentación que nos permita superar viejas dicotomías (por ejemplo, indio-español), visualizar las interrelaciones entre grupos sociales, así como la agencia de los sectores o sujetos subordinados, y, por lo tanto, a sobreponernos a las representaciones impuestas por el poder colonial — evitando así reproducir sus mecanismos de exclusión - y salir de una perspectiva que encorseta y reifica a los actores y colectividades. 
de la histaria

\section{Bibliografía}

\section{Fuentes primarias}

Archivo de la Parroquia de Santa María (APSM)

Libro de Bautismos (LB). tomos I - II

Libro de Casados (LC)

Libro de Defunciones (LD)

Archivo Histórico de Catamarca (AHC)

Archivo General de la Nación Argentina (AGN)

Sala XIII, 17-2-1. Colonia Contaduría, 1792

Manuscrito Larrouy, "Memoria de los que se hacen enterrar en dicha capilla de Santa María desde 1716”, Mayordomo Eclesiástico Ambrosio Muñíz Cancinos.

\section{Fuentes secundarias}

Acevedo, Edberto. "Situación social y religiosa de Catamarca en 1770-1771". En Primer Congreso de Historia de Catamarca. T. II: 23-98. Catamarca: Junta de Estudios Históricos de Catamarca, 1965.

Barragán, Rossana. “Categoría fiscal o categoría social? La campesinización del indio". En Cuadernos de Historia Latinoamericana, 8 (2000): 143-167.

Castillo Palma, Norma A. Cholula. Sociedad mestiza en ciudad india. México DF: Plaza y Valdés Editores, 2001.

Chance, John. Razas y clases en la Oaxaca colonial. México DF: INI, 1993.

De la Orden, Gabriela. “Cambios en la tributación indígena en Catamarca. 17651804". Ponencia presentada en el XIII Congreso Nacional y Regional de Historia Argentina. San Juan, 2005.

--- Pueblos indios de Pomán. Catamarca (siglos XVII a XIX). Buenos Aires: Dunken, 2006.

Gil Montero, Raquel. “La población colonial del Tucumán”. Cuadernos de Historia de la Población 3-4 (2006): 65-122. 
Gonzalbo Aispuru, Pilar. "La vida familiar y las movibles fronteras sociales en el siglo XVIII novohispano". Montalbán 3-4 (2001): 201-217.

Langer, Erick. "Las fuentes documentales escritas". En Formulación de proyectos de investigación, ed. Rossana Barragán, 171-182. La Paz: Fundación PIEB, 2001.

Larrouy, Antonio y Manuel Soria. Autonomía Catamarqueña. Homenaje en su primer centenario. Catamarca: D’Amico Hermanos y Talleres Gráficos Peuser, 1921.

Lockhart, James. "Organización y cambio social en la América Española Colonial”. En Historia de América Latina, ed. Leslie Bethell. T. 4: 63108. Barcelona: Crítica, 1990.

López de Albornoz, Cristina. “'Naturales', 'bárbaros', 'miserables': el discurso liberal y el trato a los pueblos aborígenes tucumanos en las primeras décadas del siglo XIX". En Actas del $1^{\circ}$ Congreso de Investigación Social. 412-419, San Miguel de Tucumán: Universidad Nacional de Tucumán, 1996.

--- Los dueños de la tierra. Economía, Sociedad y Poder. Tucumán, 1770-1820. Universidad Nacional de Tucumán, San Miguel de Tucumán, 2003.

Lorandi, Ana María. "La resistencia y rebeliones de los diaguito-calchaquí en los siglos XVI y XVII”. Revista de Antropología 6 (1988): 3-17.

--- De quimeras, rebeliones y utopías. La gesta de Pedro Bohórquez. Lima: Pontificia Universidad Católica del Perú, 1997.

--- "Las rebeliones indígenas". En Nueva Historia Argentina. Tomo La sociedad colonial, dir. Enrique Tandeter, 287-329. Buenos Aires: Sudamericana, 2000.

--- y Boixadós, Roxana. "Etnohistoria de los valles Calchaquíes en los siglos XVI y XVII”. RUNA 17-18 (1987-1988): 263-419.

--- y Mercedes del Río. La Etnohistoria: Etnogénesis y Transformaciones Sociales Andinas. Buenos Aires: Centro Editor de América Latina, 1992. 
McCaa, Robert. "Calidad, Clase and Marriage in Colonial México: The Case of Parral, 1788-1790. HAHR 64-3 (1984): 477-502.

Montes, Aníbal. "El gran alzamiento diaguita (1630-1643)". Revista del Instituto de Antropología 1 (1959): 81-159.

Piossek Prebisch, Teresa. El Inca del Tucumán. Buenos Aires: Ed. Juárez, 1976.

Punta, Ana Inés. "La tributación indígena en Córdoba en la segunda mitad del siglo XVIII". Revista Andes. Antropología e Historia, 6 (1994): 4978 .

Rasini, Beatríz. "El censo de 1771". Anuario del Instituto de Investigaciones Históricas 6 (1962-1963): 43-57.

Rodríguez, Lorena. "Una aproximación a la reconfiguración del valle Calchaquí”. Anales. Nueva Época 6 (2003): 365-394.

--- "Migraciones en los Andes meridionales. El caso de los atacameños en Santa María durante la segunda mtitad del siglo XVIII". Revista Andina, 39 (2004): 103-123.

--- "Después de las desnaturalizaciones. Reconfiguraciones socio-económicas y étnicas en el valle de Santa María (fines del siglo XVII - fines del XVIII)". Tesis doctoral, Universidad de Buenos Aires, Buenos Aires, 2007.

Ruggeroni, Dante. "El padrón militar de 1812". Anuario del Instituto de Investigaciones Históricas 6 (1962-1963): 13-30.

Saignes, Thierry. “¿Es posible una historia chola del Perú?”. Alpanchis 2 (1990): 635-657.

Wachtel, Nathan. El regreso de los antepasados. Los indios urus de Bolivia del siglo XX al XVI. Ensayo de historia regresiva. México DF: Fondo de Cultura Económica, 2001.

Zavala, Silvio. Los esclavos indios en Nueva España. México DF: El Colegio Nacional, 1994.

Fecha de recepción: 17 de mayo de 2008

Fecha de aprobación: 25 de septiembre de 2008 